\title{
The Role of Social Capital in the Creation of Community Wireless Networks
}

\author{
Abdelnasser Abdelaal Hesham Ali Deepak Khazanchi \\ College of Information Science and Technology \\ University of Nebraska at Omaha \\ Omaha, NE 68182 \\ \{aabdelaal, hali, khazanchi\}@mail.unomaha.edu
}

\begin{abstract}
Community wireless networks (CWNs) offer free or affordable Internet access for the purpose of improving the well-being of the community. Many questions have been raised about the ownership, sustainability, and social and economic implications of CWNs. To address these concerns, we propose a conceptual framework that describes the role of social capital in the creation of CWNs. This framework takes into account a number of collective actions and cooperative activities that contribute to the development of CWNs. These actions and cooperative activities include donating money and hardware, volunteering manpower and technical skills, developing open source software for the network, and sharing wireless nodes with peers. We used the collective actions and cooperation construct of the social capital concept to attribute these types of community contributions. We collected data via a survey to support the proposed framework. The primary implication for practitioners is that mobilizing embedded resources in communities can build a common wireless infrastructure for their digital needs. This study is an important step towards advancing this topic as an intellectual stream.
\end{abstract}

\section{Introduction}

Affordable Internet access has become essential for improving people's livelihoods. However, 80 percent of the world's population has limited access to the Internet, particularly rural and underserved communities. Such communities are lagging behind, in the digital sense, because they cannot take advantage of the social and economic opportunities of the Internet. Community wireless networks (CWNs) have emerged as grassroots connectivity solutions for such devastated societies [1, 15, 22, 24, 27, and 29]. CWNs are clusters of socio-technical networks funded, implemented, and operated by the community in order to provide free or affordable Internet access to its members [21]. The rise of these common infrastructures is driven mainly by the advancements of wireless technologies, unlicensed spectrum, contributions of volunteers, open source software and hardware, and the explosive growth of home networking and public WiFi hotspots [4, 24, and 27].

Developing these cooperative networks requires a motivated and committed group of people with shared objectives and strong social ties who work and contribute for the well-being of their community [4, 7 14, 18, 24, and 27]. In other words, CWNs are built and operated using community resources (e.g., time, money, skills, and computer resources). As with other collective projects, the greatest challenge facing CWNs is not technical (e.g., building the wireless network) but social: engaging the community, sustaining volunteers and donors, attracting a wide range of users and adopting a sustainable business model [1, 14, 23, 29, 18, 24, and 27].

These networks were built by technology developers primarily to obtain technical expertise. However, they have been redirected to achieve societal objectives [18, 24, and 27]. Besides providing free Internet access, CWNs serve as social venues where community members meet to deal with financial, legal, implementation and management issues. Community members hold discussion forums and awareness events, solicit feedback from community members, and coordinate related logistic activities. They also donate money and hardware, volunteer time and manpower, develop Open Source Software (OSS) for the system, and share their nodes with their neighbors. These collective actions and cooperative activities are driven by the social capital in the community. The construct of collective action and cooperation refers to how community members work together to achieve common goals. It shows that achieving collective actions is possible only if sufficient social capital is available in the community [26]. The major exception occurs in totalitarian societies when governments force people to work together on collective actions or common projects. While some scholars consider collective actions and cooperation as outcomes of social capital $[8,12$, and 13], others consider them one of the social capital dimensions [8 and 26]. 
The social capital concept refers to social ties, norms, obligations, cooperation, trust, and embedded resources in social structures that achieve collective actions [2, 3, $8,10,12$, and 17]. It shows that having access to social resources can generate positive socioeconomic outcomes [8]. These resources may include information, ideas, knowledge, connections or any form of resources that could be shared with others [10].

Social capital can enhance economic achievements, alleviate poverty, increase income, accrue human capital (e.g., skills, knowledge), improve health care, decrease transaction costs, and enhance child welfare $[2,26]$. In the digital domain, social capital of volunteers has created OSS, wikis, virtual communities, and many other digital products and electronic tools $[19,29]$. Previous studies that address the relationship between social capital and the Internet have focused on whether the Internet increases or decreases social capital. Our objective is to complement previous literature by exploring the dual version of this relationship. In particular, we address the role of social capital in the creation of CWNs. The specific research question we address is:

What is the contribution of social capital to the creation of CWNs?

To answer this question, we explored different forms of collective actions and cooperative activities achieved by community members in order to develop these networks. We situated these collective actions in the social capital research stream, because some scholars consider the construct of collective actions and cooperation an outcome of social capital [8, 12], and others consider it one of the social capital dimensions [26]. This study is motivated by the following:

(i) Rural and underserved communities lack the sufficient commercial incentives to attract telecommunication companies because of low population density, remote location, low income, or harsh geography [1]. Therefore, empowering volunteers and relying on the social capital in the community may be the only viable way to include these communities in the digital age.

(ii) At this embryonic stage, it is necessary to describe the evolution of such grassroots networks within their social settings. Such description is important for us to understand the heavy confluence between their social factors and technical factors; and, this is important to advancing this innovation as a research stream.

The rest of this paper is organized as follows: the following section discusses the literature of the relationship between social capital and CWNs. Then we presented the used research methodology. In the fourth section, we analyzed the collected data and attributed the collective actions in the domain of CWNs. In the fifth section, we linked the factors of CWNs to the dimensions of social capital identified by different scholars. In the sixth section, we discussed the significance of our research and suggested some ideas for future work. We concluded our study in the last section.

\section{Literature review}

It is important to point out that CWNs lie at the confluence of social networks, nonprofit organizations, and emerging wireless technologies [21]. We believe that these three dimensions should be considered in order to advance this research stream. The business model concept has been used to address the business aspects of these networks, such as value offerings, finances, target customers, infrastructure management, and stakeholders [1, 9, and 25]. The main technical variables of CWNs are choosing the proper technology, assuring quality of service (QoS) and security, optimizing resource allocation, and supporting device roaming between different wireless clouds [1, 25, and 29]. Our study complements previous research related to the design of CWNs by exploring the social factors of these networks. Therefore, our review of the literature focused on the outcomes of social capital in the domain of CWNs.

\subsection{The social capital concept and collective actions}

Nahapiet and Ghoshal recognize three dimensions of social capital: (1) structural: the pattern of relationships linking actors, (2) relational: social relationships between individuals, and (3) cognitive: shared meaning and understanding [12]. They distinguish between social capital and its consequences. We focused only on the outcomes of social capital with respect to CWNs. Lin defines social capital as "resources embedded in social structures which are accessed and/or mobilized in purposive actions" [8]. He identifies three components of social capital: resources embedded in social structures; accessing these resources by individuals; and mobilizing such resources by individuals to achieve purposive actions. Woolcock defines social capital as the norms and networks that facilitate collective actions [17]. He notes that it is difficult to determine whether social capital is the infrastructure itself, the content of social relations, the medium, or the outcome. According to Coleman, social capital is intangible; fungible; and context specific; exist only among groups rather than individuals; and difficult to measure [2]. Coleman recognizes three components of social capital: 
obligations and expectations, information channels, and social norms.

Quan-Haaseand and Wellman point out that the concept of social capital is used interchangeably with social contact or civic engagement [11]. Social contact includes interpersonal communications such as visits, encounters, phone calls, and social events in general. Civic engagement refers to the degree to which people become involved in their community. Civic engagement and volunteerism are at the heart of our study. Resnick views social capital as an input/output model that has the following sources of social capital: communication paths, common knowledge, shared values, collective identity, obligations, roles and norms, and trust [13]. Its outputs include information routing, resource exchange, emotional support, coordination, and collective action.

\subsection{CWNs and social capital}

In previous work, we describe a CWN as two networks: a wireless network and a social network served by this wireless network [21]. In this description we parse out the social, economic, and technical factors of CWNs in order to help researchers address them in a quantitative manner. Sligo and Wallace argue that providing free Internet in New Zealand strengthens community connectedness, improves civic engagement, and increases neighbors' ties [16]. Huysman and Wulf point out that those electronic networks create social capital [3]. Kavanaugh and Patterson state that community computer networks positively impact social capital because they increase access to the information society [6]. Joseph examined the role of WiFi-enabled public libraries in creating social capital [5]. The findings indicate that establishing a café and/or wireless Internet can significantly increase the community's use of the library. Abdelaal and Ali classified different cooperative business models for implementing CWNs [1]. The authors attribute types of cooperation and partnerships between stakeholders of CWNs.

Quinn used multiple case studies to develop a guide that highlights the role of community engagement, volunteerism, OSS, and donated computers and other hardware in the creation of these systems [14]. According to Quinn, engaging the community was achieved through word of mouth, fliers, especial events, mailing lists, community meetings, and community newsletters.

Simpson argues that social capital boosts the sustainability of community informatics projects [7]. According to Simpson, social capital is important for realizing community capacity, building the shared understanding of the benefits of these projects, and exploring the capability of such initiatives in building new forms of social structures. It also enables community ownership of the infrastructure. Additionally, it fosters social inclusion, increases community interaction, and boosts community cohesiveness.

Quan-Haase and Wellman note that empirical studies that investigated the relationship between social capital and the Internet have yielded mixed results [11]. The authors categorize their findings into four scenarios: diminishing social capital, transforming social capital, supplementing social capital, increasing social capital, or accruing a new form of social capital that cannot be measured using mainstream standards.

The construct of collective action and social dilemmas theory have been used to explore the motivations of CWNs' participants [18]. The authors propose a taxonomy of participants to explain how individuals solve the social dilemmas associated with their participation.

A multiple case study attributes CWNs as cooperative actions that have been created by developers to obtain technical expertise [24]. Its findings show that these networks have little impact on democracy, social capital, and economic development. The authors, however, note that these networks generate social ties and promote knowledge in the community. Meinrath calls WCNs "open infrastructures" and he proposes a research agenda and a plan of actions for boosting these networks [27]. The Wireless Leiden, Netherlands, network used low cost network technologies, OSS, home-built antennas, and voluntary manpower and technical support to build a wireless infrastructure that provided wireless internet at a very low cost [19]. We attribute such resources used to build Wireless Leiden as collective actions driven by the social capital in the community. Shin and Venkatesh analyze the wireless network of Kutztown Community [28]. The authors suggest that community participation should continue through all development stages in order for these networks to be sustainable.

\section{Research methodology}

Previous literature shows that community networks build social capital [3, 5, 6, and 7]. Our study focuses on the dual version of this relationship. In particular, we explore the outcomes of mobilizing the social capital of local communities to build a wireless network for their use. These outcomes are the collective actions and cooperative activities incurred using embedded resources (e.g., social values, technical skills, time, donations, and computer resources) in the community while developing these networks. We adopted the social capital notion of the World Bank that recognizes six 
dimensions for social capital: groups and networks, trust and solidarity, information and communication, empowerment and political action, social cohesion and inclusion, collective action and cooperation [26]. We collected data about these six dimensions, but this paper presents only the collective actions and cooperation in the domain of CWNs. The construct of collective actions and cooperation measures how community members have cooperated to achieve collective objectives [26]. It also considers the consequences of violating community expectations, but we do not address this dimension. We used a survey instrument to collect data from CWN activists during their annual summit ${ }^{1}$. We chose this summit as a venue for the data collection process because of the diversity of its attendees and their expertise in this domain. They included project managers, volunteers, donors, civil activists, advocates and technology vendors. The data has been collected at the level of projects.

We used the short version (or the core questions) of the World Bank instrument after modifying it to suit our subject [26]. In particular, we modified questions $3.2,3.3,3.5$, and 3.6 of this questionnaire. We added questions to collect data about other facets of community contributions such as money and hardware donations, sharing access points with peers, providing technical support, and developing software for the system. Identifying these types of contributions has been made based on extensive review of literature, experience of working on one of CWNs projects ( the Omaha Wireless), and discussions with leaders of CWNs during their annual summit. Seven judges tested the relevance of these questions to our subject.

\section{The collective actions in the domain of CWNs}

We received 41 responses representing $28 \mathrm{CWNs}$ from different parts of the world. We eliminated the incomplete answers. Around 77 percent of these networks do not charge users for Internet access. Following is a discussion of the collected data about forms of collective actions and cooperation in the domain of CWNs.

\subsection{Money donations}

This factor measures the amount of money donations the project received from community members, business partners, foundations, technology vendors,

\footnotetext{
1 The International Summit for Community Wireless Networks was held in Washington, DC, U.S., May $28^{\text {th }}$ to the $30^{\text {th }}$, 2008. Its objective was to explore the opportunities and challenges of CWNs.
}

municipalities, and other donors. Our discussions with community leaders during the summit revealed that money donation is a key factor for developing common and free wireless networks, particularly in rural and underserved areas.

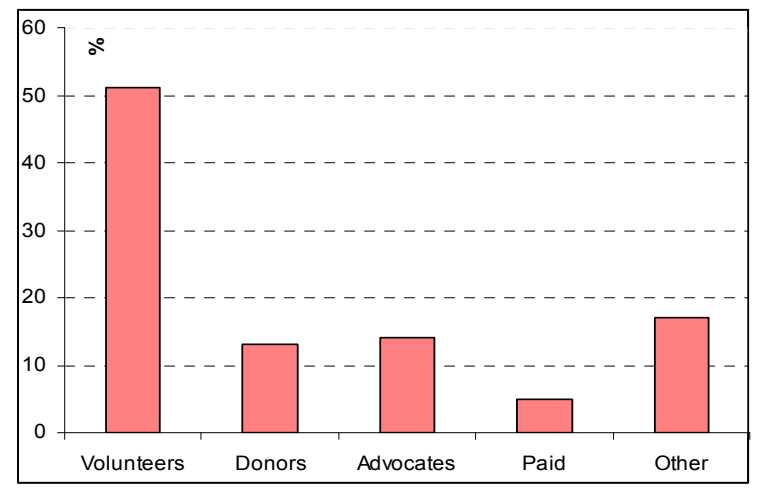

Figure 1: The contributors of CWNs

About 13 percent of survey respondents donated money to build the system, as shown in Figure 1. Table 1 shows the amounts of money donations that investigated projects received. For instance, the AirStreem network received $\$ 10,000$ of donations. Pretoria Wireless received $\$ 3,000$ in donations.

\subsection{Hardware donations}

Hardware donations are an important form of contribution by partners and community members to build low-cost CWNs [1, 14, and 27]. We measured this factor by the number of used or new PCs, routers, access points that have been donated for the project. Table 1, column 7, shows the donated PCs or access points that projects received. For instance, Nepal Wireless received 50 PCs as a donation. Donated hardware was important in building CUWiN, Austin Wireless, the Omaha Wireless network, and many others. Hardware donors may include community members, technology vendors, local businesses, IT recycling programs, and others. For instance, the New Orleans network was built using donated equipment after Hurricane Katrina in order to connect survivors with relatives and assist with rescue activities [14]. Cisco Incorporation donated two access points to the OmahaWireless project. Recycling programs (e.g., Dell, IBM, and HP) cooperate in these initiatives. Moreover, some CWNs (e.g., NYC Wireless, Omaha Wireless, and Austin Wireless) facilitate recycling used PCs for needy community members to enable them to use the system. 
Table 1: Forms of contributions of communities in developing CWNs

\begin{tabular}{|c|l|l|l|l|l|l|l|}
\hline & \multicolumn{1}{|c|}{ CWN } & \multicolumn{1}{c|}{ Time } & \multicolumn{1}{c|}{ Money } & Tech. Sup. & Sharing & Hardware & OSS \\
\hline 1 & Court Housing Co-op & 1 & 200 & 1 & 2 & 2 & 0 \\
\hline 2 & SeattleWireless & 20 & 5,000 & 5 & 20 & 0 & 0 \\
\hline 3 & AirStream & 50 & 10,000 & 0 & 0 & 0 & 0 \\
\hline 4 & Bristol Wireless & 100 & 100 & 100 & 0 & 0 & 0 \\
\hline 5 & Keur Sedaro & 3 & 30 & 2 & 5 & 0 & 0 \\
\hline 6 & Pretoria Wireless & 0 & 3,000 & 0 & 0 & 0 & 0 \\
\hline 7 & Cstle Square WiFi & 65 & 60,000 & 115 & 0 & 0 & 0 \\
\hline 8 & WUG & 100 & 50,000 & 24 & 6 & 1 & 0 \\
\hline 8 & Cape Town Wireless & 4 & 3,895 & 40 & 6 & 20 & 1,000 \\
\hline 9 & Red Libre De Ometepe & 5 & 30000 & 2 & 2 & 30 & 50,000 \\
\hline 10 & Jawug & 2 & 389 & 2 & 30 & NA & 0 \\
\hline 11 & NYCwireless & 2 & 0 & 2 & 4 & 0 & 0 \\
\hline 12 & Inveneo & 7 & 0 & 10 & NA & NA & 0 \\
\hline 13 & Zgwireless & 20 & 0 & 20 & 100 & 3 & 0 \\
\cline { 2 - 7 } 14 & Nepal Wireless & 10 & 30,000 & 10 & 25 & 50 & 10,000 \\
\hline
\end{tabular}

\subsection{Volunteerism}

This category refers to the contributions of community volunteers in terms of time and labor to build and operate the network [1, 14, and 27]. Efforts of volunteers are very important in order to obtain the necessary political and social support for the project and help in fundraising events. They also explore community assets, recruit participants, and explore possible locations for installing the infrastructure. We measured this factor by percentage of volunteers to the total number of respondents as presented in Figure 1, the number of weekly volunteered hours, Table 1, and the number of monthly meetings held by the group as shown in Table 2. About 51 percent of the respondents are volunteers and 15 percent are advocates of these networks, as illustrated in Figure 1. The number of volunteers in the 28 investigated projects is 330 , with an average of 11 volunteers for each project. The third column in Table 1 shows the total voluntary hours per week for selective projects. For instance, volunteers give 20 hours per week for SeattleWireless and 50 hours for AirStream. Table 2 shows the number of monthly meetings held by the participants. Participants of Funkfeuer met 10 times during the month before conducting the survey. The Cape Town Wireless community met twice that month. Scholars consider purposeful meetings as a form of social capital.

Practitioners note that the need for volunteers usually decreases after the implementation phase. In addition, after the implementation of the project, managing volunteers may become very difficult.

\subsection{Node sharing}

Node-sharing refers to the type of cooperation in which community members share their nodes (e.g., access point or router) with their neighbors to expand the network. They may share their node for free or divide the cost among members. In this case, community members are investors, owners, and managers of the network. In other words, these networks are an aggregation of Wi-Fi hotspots owned by community members and local businesses. We measured this facet of cooperation by the number of community members who share their access points with their neighbors. The sixth column in Table 1 shows that the number of individuals who share their access points with others is 30 in the Jawug network and 25 in Nepal Wireless. The NYC Wireless (New York, U.S.) and the B.C. Wireless project (British Columbia, Canada), and many others are built on the notion of node-sharing. The main advantage of this form of cooperation is reducing the implementation and operation costs of the network, since node owners invest in the network and manage it. In addition, node-sharing builds the sense of community ownership.

A similar form of cooperation is node-hosting, where network leaders negotiate with an individual or a business to host a node in order to cover a specific area. It is important to install the system facilities (e.g., routers, antennas, towers) at specific venues (e.g., tall buildings, light poles, central buildings) in order to provide good coverage $[1,14,21]$. In node-hosting, the host neither owns nor manages the node, unlike the case of node-sharing process. 
Table 2: Meetings per month

\begin{tabular}{|r|l|r|}
\hline & CWN & Times \\
\hline 1 & Funkfeuer & 10 \\
\hline 2 & Court Housing Co-op & 3 \\
\hline 3 & SeattleWireless & 0 \\
\hline 4 & Champain-Urbana & 10 \\
\hline 5 & OmahaWireless & 0 \\
\hline 6 & AirStream & 0 \\
\hline 7 & Faithful & 5 \\
\hline 8 & OpenGermania & 0 \\
\hline 9 & Pretoria Wireless & 0 \\
\hline 10 & WUG & 3 \\
\hline 11 & Cape Town Wireless & 2 \\
\hline 12 & Nepal Wireless & 4 \\
\hline 13 & Red Libre De Ometepe & 15 \\
\hline 14 & Jawug & 5 \\
\hline 15 & NYCwireless & 0 \\
\hline 16 & Personal Telco & 8 \\
\hline 17 & Netequaty & 10 \\
\hline 18 & Inveneo & 2 \\
\hline 19 & Dharamsala Wireless & 3 \\
\hline 20 & ZGwireless & \\
\hline & & \\
\hline
\end{tabular}

\subsection{Developing Open Source Software (OSS)}

Another driving factor for CWNs is using free software and open source hardware to build the network [14 and 27]. CWNs require affordable technical solutions. In fact, CWNs have been seen as an outgrowth of the free OSS community. Similar to OSS groups, technology developers and advocates of CWNs cooperate and develop software and hardware for the system and homebuilt hardware and share it with other nonprofit CWNs [14, and 27]. For instance, they developed CUWiNware software, Postnuke, the cantenna antenna, FreeBSD, RONJA, Meraki Mini, and Fonero router. Such products have reduced the implementation and operation costs of Seattle Wireless, NYC Wireless, Austin Wireless, Wireless Leiden, and many others. It is not easy to measure this factor because of the difficulty to track contributions of individuals in developing OSS. Therefore, we measured this construct by the estimated market value, in U.S. dollars, of the OSS used in building the system. For instance, they saved Air-Stream $\$ 10,000$ and Cape Town Wireless $\$ 1,000$, as shown in Table 1 .

\subsection{Technical support}

This form of cooperation refers to the technical support, troubleshooting, and training that community members provide to the network. The development and sustainability of these networks depend, in large part, on the availability of voluntary technical support from community members and partners [14, 19, and 27]. This measure reflects the cognitive contributions of the community in supporting the project. We used two measures to assess this factor: (1) the weekly hours that community members contribute in troubleshooting or maintaining the network as shown in Table 1, (2) and the willingness of community members to help if technical support is needed as presented in Table 3. Table 3 shows that 65.8 percent of respondents say it is "very likely" that participants will help when there is a technical problem. Another 18.4 percent are "somewhat likely" to help. This means that the cognitive contribution of the community is very high in these projects.

The most important technical events are 'nodeconstruction parties' where community activists, network operators, students, computer geeks, and others cooperate to build a new node [14, and 27]. There are other collective actions achieved through nodeconstruction parties such as:

(i) Boosting the publicity of the project;

(ii) Educating the community about project issues and benefits;

(iii) Creating a sense of community ownership that empowers volunteerism;

(iv) Sharing knowledge and technical expertise; and

(v) Strengthening social ties among members.

The lessons learned in this regard show that it is difficult to recruit skillful volunteers in developing societies. Therefore, these networks (e.g., Wireless Ghana and Champaign-Urbana) usually provide training to volunteers and network users to bridge this gap.

Table 3: The willingness to help in technical issues

\begin{tabular}{|l|l|l|}
\hline & $\%$ & Participants \\
\hline Very likely & 65.8 & 25 \\
\hline Somewhat likely & 18.4 & 7 \\
\hline $\begin{array}{l}\text { Neither likely or } \\
\text { unlikely }\end{array}$ & 13.2 & 5 \\
\hline Somewhat unlikely & 0 & 0 \\
\hline Very unlikely & 2.6 & 1 \\
\hline
\end{tabular}


Eighty percent of the investigated projects provide free basic computer training to volunteers and network users; and this is another form of collective actions achieved in the domain of CWNs. However, we will discuss it when we address the benefits of community members incurred from their participation. The difference between this type of collective action and developing OSS is that the first is embedded in the local community, while OSS contributions may involve volunteers from outside the local community. Therefore, technical skills could be inputs to build the system or one of its outputs. That is why we separate this cognitive collective action from traditional volunteerism of manpower and time.

\section{Linking CWNs' collective actions to the social capital concept}

In Figure 2, we proposed a framework that encompasses the collective actions achieved in the domain of CWNs and their relationship with social capital. It shows that the norms, social networks, and embedded resources in communities fuel voluntary work, money donations, node-sharing, and hardware donations in order to build and operate the network [14]. Table 4 links these collective actions to related mainstream dimensions of social capital attributed by scholars.

Although community contributions take many forms, each of these forms has two characteristics in common: (1) Individuals acting in isolation cannot achieve these collective actions; instead, they create new associations and networks that contribute for the community cause or public good. (2) Such social structures produce or reproduce technical skills, spare time, used hardware and other resources to build the network. Therefore, we argue that the contributions of communities to the development of these networks are also collective actions, particularly when we consider that CWNs have been described as commons [4], collective actions [18], cooperative actions [24], open infrastructure [27], and public wireless networks [29]. CWNs create new opportunities, broaden perspectives, stimulate new ideas, and build friendships and leadership. In addition, most of these CWNs do not charge users for Internet access.

We argue that these collective actions are driven by the social capital embedded in the community for three reasons: (1) CWNs generate social capital; (2) collective actions and cooperation are achieved only when sufficient social capital exists in the community [26]; and (3) social capital boosts CWNs [7]. Our work provides specifics on the role of social capital in boosting CWNs when we identify and describe community contributions in this regard.

Volunteerism is the spirit of social capital $[8,26]$ and the fuel of CWNs as well [1,14, and 25]. It is a form of cooperation that is embedded in the community, not in single individuals. Volunteers contribute information, time, and effort to build a network that serves the community at large.

The cooperation of node-sharing and node-hosting are embedded in the community and they are a form of civic engagement. These types of cooperation require intense face-to-face communications and negotiations with property owners to convince them to host a node or share their nodes with others. In addition, they require trust between community members. Moreover, they build the sense of community and this is the sprit of social capital, particularly its structural and relational dimension [12].

Money and hardware donors give because of the trust and reciprocity they expect from community members. According to Lin, social capital is an aggregation of valued resources (e.g., economic, political, cognitive, cultural, or social) embedded in social structures [8].

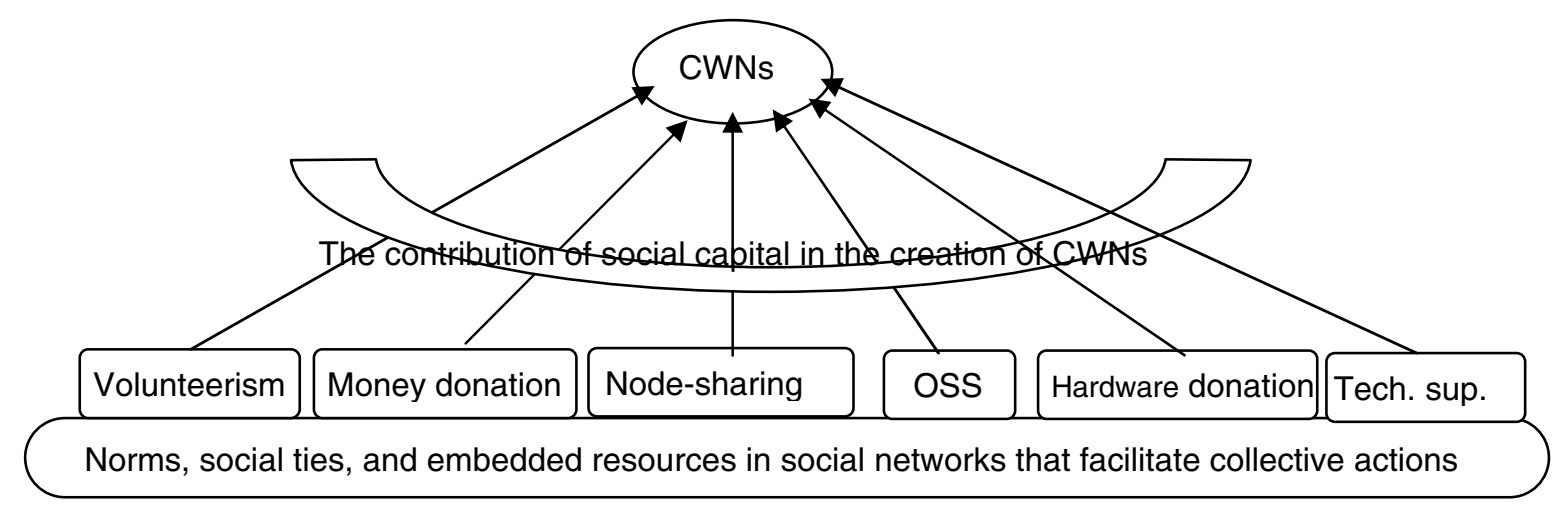

Figure 2: The contributions of social capital in the creation of CWNs 
Table 4: Linking CWNs collective actions to social capital dimensions

\begin{tabular}{|l|l|}
\hline \multicolumn{1}{|c|}{ Collective action } & \multicolumn{1}{c|}{ Social capital dimension } \\
\hline Volunteerism & $\begin{array}{l}\text { Collective actions and cooperation [26], information, embedded } \\
\text { resources or purposive action [8], structural [12] }\end{array}$ \\
\hline Money and hardware donations & $\begin{array}{l}\text { Collective actions and cooperation [26], relational [12], embedded } \\
\text { resources or purposive action [8] }\end{array}$ \\
\hline Node-sharing & $\begin{array}{l}\text { Collective actions and cooperation [26], embedded resources or } \\
\text { purposive actions [8], relational [12] }\end{array}$ \\
\hline OSS and technical support & $\begin{array}{l}\text { Collective actions and cooperation [26], embedded resources or } \\
\text { purposive actions [8], information [26], cognitive [12] }\end{array}$ \\
\hline
\end{tabular}

Coleman believes that acquiring information necessary to facilitate actions is costly [2]. However, sharing information with people reduces the cost of acquiring it. He emphasizes that such information is a form of social capital. Accordingly, the information, technical expertise and other cognitive contributions of communities (e.g., developing OSS and hardware, and providing technical support) in building CWNs are outcomes of social capital in the community. These outcomes are driven by the social relationships and cognitive dimensions of social capital that have been attributed in [8, 12, and 26]. They also contribute to the overall collective action which is the creation of CWNs. This is the spirit of the social capital concept as discussed earlier. In general, community engagement and voluntary groups lie at the heart of the social capital concept [8 and 26].

Coleman states that social capital is embedded in social networks and achieves certain actions that could not be achieved without it [2]. These are the exact properties that apply to the contributions (e.g., volunteerism, money and hardware donations, nodesharing, developing OSS) of community members to build CWNs as shown in Figure 2 and Table 4.

The proposed framework could be modified to include or exclude specific facets of community contributions or collective actions to reflect social settings. Although we separate these six dimensions of collective actions analytically, we recognize that some of them are highly interrelated such as volunteerism and technical support. We have coded them into different factors for the purpose of simplicity and for helping researchers control and measure these factors in the future.

\section{Implications for practice and research}

In this research study, we have identified and attributed the collective actions and cooperative activities that contribute to the development of CWNs. They include volunteerism, money and hardware donations, OSS contributions, and node-sharing. We have identified these actions separately because, we believe, they represent important potential set of resources for developing CWNs. These resources have not yet discussed either in the mainstream literature of the outcomes of social capital or in the literature of CWNs. We provided evidence to show the role of these types of collective actions and cooperation in the development of CWNs. While volunteerism, donations, and engagement in community issues are the essence of social capital as indicated by scholars, these types of resources are also essential for the development of common CWNs that provide free Internet access. We have focused on the functional aspects of social capital or the collective actions it can achieve in the realm of CWNs. This study has the following practical implications:

(i) Operationalizing the social capital embedded in the community is important for developing selfsustainable CWNs.

(ii) It is important to base the adopted implementation model on the potential contributions of the community. This is important in order for these grassroots networks to be sustainable and mature.

The primary intellectual contribution of this study lies in describing the creation of CWNs within their social context. While the literature shows that community networks, and the Internet in general, create social capital, we showed that social capital contributes to the creation of CWNs. In addition, this work improves our understanding of the social capital concept and its potential outcomes in the digital domain.

The proposed framework is a first step towards addressing the dual causality between social capital and CWNs. This framework could be used to guide future work on this topic. It would help researchers to address relevant issues, determine proper unit and level of analysis, and identify future research in this contemporary area. In particular, it would help researchers to answer questions related to who, what, how, and why, when addressing community 
contributions in CWNs. For instance, who are the main contributors of CWNs and what are their benefits? Why do community members contribute to CWNs? What are the main management issues? How can we aggregate and measure their tangible and intangible contributions and benefits?

The main limitation of this framework is the difficulty of aggregating the tangible and intangible contributions of the community in order to assess their contributions in the total cost of the project. Another limitation is the difficulty to assess the contribution of each of the discussed collective action in the overall implementation and operation costs of the network.

In our analysis, we pointed out the important facets of collective actions and cooperation, rather than review such actions thoroughly. We will expand this multidisciplinary study in the future to empirically test the relationship between the collective actions in the domain of CWNs and other dimensions of social capital. We will also investigate the role of these networks in creating human capital and physical capital.

\section{Conclusion}

The evolution of CWNs shows the significance of social capital embedded in communities and its role in boosting digital inclusion. We proposed a framework that encompasses the role of collective actions and cooperation in the creation of CWNs. These collectives include OSS, money donations, providing technical expertise, voluntary work, node-sharing, and hardware donations. We attributed these collective actions as outcomes of the social capital embedded in the communities.

This study improves our understanding of the capabilities of social capital, specifically in the digital domain. It shows that social capital constitutes a valuable resource for community development, taking advantage of digital innovations. The relationship between CWNs and social capital is expected to gain more attention from the scientific community. This is mainly due to the explosive growth of groups and communities that develop hardware and software products for the public use.

\section{Acknowledgement}

\section{References}

[1] A. Abdelaal and H. Ali, "Typology for Community Wireless Network Business Models," Proceedings of the Thirteenth Americas Conference on Information Systems, August 9-12th, Keystone, Colorado, USA, 2007.
[2] J. Coleman, "Social Capital in the Creation of Human Capital," American Journal of Sociology, V94, 1988.

[3] M.H. Huysman and V. Wulf, "Social Capital and IT, current debate and research," MIT Press: Cambridge, 2004.

[4] J. Damsgaard, M. A. Parikh, and B. Rao, "Wireless commons perils in the common good," Communications of the ACM 49(2): 104-109, 2006.

[5] B. Joseph, "Social capital, Community, and Public Libraries: An examination into how coffee and wireless internet access can increase our quality of life," A Master's Paper for the M.S. in L.S degree. April, 2006.

[6] A. Kavanaugh, and S. Patterson, "the Impact of Community Computer Networks on Social Capital and Community Involvement," American Behavioral Scientist, Vol. 45, No. 3, 496-509, 2001.

[7] L. Simpson, "Community Informatics and Sustainability: Why Social Capital Matters," the Journal of Community Informatics, Vol. 1, Issue 2, pp. 102-119, 2005.

[8] N. Lin, "Building a network theory of social capital," Connections 22 (1):28-51, 1999.

[9] M. Mandviwalla, A. Jain, J. Fesenmaier, J. Smith, P. Weinberg, and G. Meyers, "Municipal Broadband Wireless Networks: Realizing the Vision of Anytime, Anywhere Connectivity," in the Communications of the ACM, 2006.

[10] P. Moran, "Structural vs. Relational Embeddedness: Social Capital and Managerial Performance," Strategic Management Journal, 26: 1129-1151 (2005).

[11] A. Quan-Haase, and B. Wellman, "how does the Internet Affect Social Capital," IT and Social Capital November 12, 2002.

[12] J. Nahapiet and S. Ghoshal, "Social capital, intellectual capital, and the organizational advantage." Academy of Management Review 23 (2), 1998, 242-266.

[13] P. Resnick, Beyond Bowling Together: Socio Technical Capital. In J. M. Carroll (Ed). HCI in the New, 2002.

[14] P. Quinn, "Community Wireless and the Digital Divide," Center for Neighborhood Technology, November 2006.

[15] E. Vos, "Reports on Municipal Wireless and Broadband Projects," March 2005 Report, from www.muniwireless.com.

[16] J. Williams, F. Sligo, and C. Wallace, "Free internet as an agent of community transformation," Journal of Community Informatics, Vol 2, No 1, 2005.

[17] M. Woolcock, "Social Capital and Economic Development: Toward a Theoretical Synthesis and Policy Framework," Theory and Society, Vol. 27, No. 2, April, 1998, pp. 151-208.

[18] M. Bina and G.M. Giaglis. "Unwired collective action: Motivations of wireless community participants," In Proceedings of the 5th International Conference on Mobile Business (ICMB), June 26-27 2006.

[19] R. Drunen, J. van Koolhaas, H. Schuurmans, and M. Vijn, "Building a wireless community network in the Netherlands" USENIX/Freenix Conference, June, 2003. 
[20] R. M. Duron and C. E. García, "Returns from Social Capital in Open Source Software Networks," accessed September 5, 2008, from http://www.business.mmu.ac.uk/emaee/papers/49Garcia \&Mendez-Duron.pdf

[21] A. Abdelaal and H. Ali, "A Graph Theoretic Approach for Analysis and Design of Community Wireless Networks," to appear in Proceedings of the Thirteenth Americas Conference on Information Systems, 14-17th August, Toronto, Ontario, Canada, 2008.

[22] B. Rao, and M. Parikh, "Wireless broadband drivers and their social Implications," Technology in Society Vol. 25, November, 477-489, 2003.

[23] A. Hars, and S. Ou, "Working for free? Motivations for participating in open-source projects," International Journal of Electronic Commerce, 6 (3), 25-39, 2002.

[24] C. Sandvig, "An Initial Assessment of Cooperative Action in WiFi Networking," Telecommunications Policy, 28, 2004, pp. 579-602.

[25] Cisco Inc., "Municipalities Adopt Successful Business Models for Outdoor Wireless Networks," accesses February 28, 2007, from ttp://www.cisco.com/en/US/netsol/ns621/networking_sol utions_white_paper0900aecd80564fa3.shtml.

[26] C. Grootaert, D. Narayan, V. N. Jones V. N. Jones, and M. Woolcock, "Measuring Social Capital: an Integrated Questionnaire," accessed January 5th, 2008, from: http://povlibrary.worldbank.org/files/11998_WP18Web.pdf

[27] S. Meinrath, "Community Wireless Networking and Open Spectrum Usage: A Research Agenda to Support Progressive Policy Reform of the Public Airwaves," The Journal of Community Informatics, Vol. 1, issue 2, pp. 204-209, 2005.

[28] D.H. Shin and M. Venkatesh, "Analysis of the Development of Kutztown Community Network," Proceedings of the Proceedings of the 41st Annual Hawaii International Conference on System Sciences, 2008.

[29] C. Middleton, G. Longford, A. Clement and A. B. Potter, "ICT Infrastructure as Public Infrastructure: Exploring the Benefits of Public Wireless Networks," the proceedings of the 34th Research Conference on Communication, Information and Internet Policy, 2006. 